\title{
A122 円管開口端における衝擊的騒音のパッシブコントロール
}

\author{
九大·総理工 青木俊之 九大·院仲尾晋一郎 \\ 九大・総理工 近藤信昭 九大・総理工 松尾一泰
}

Passive Control of Impulsive Noise from an Open End of a Circular Tube

Toshiyuki AOKI*, Shinichiro NAKAO*, Nobuaki KONDOH* and Kazuyasu MATSUO*

\begin{abstract}
When a high-speed train enters a tunnel, a compression wave is generated ahead of the train and propagates along the tunnel. This wave subsequently emerges from the exit portal of the tunnel as an impulsive wave which may cause noise problems in the surrounding area. The objective of this paper is to show the optimum silencer to reduce an impulsive noise. The effects of the annular boxes at the circular tube exit on the impulsive noise were investigated numerically. As a result, the effects of geometry of passive silencer and the noise reduction rate have been clarified, and then a suitable choice of design factors for exit anular box has been suggested.
\end{abstract}

\section{1.まえがき}

高速列車のトンネルへの突入により形成される圧縮波は，トンネル内を伝ぱレトンネル出ロから放出されると衝撃的 騒音になる。従来の低減対策1,2)は，トンネル入口での緩衝工，トンネル内に枝坑を設けるなどの方法であったが，近 年の列車の高速化に伴い従来の低減法では不十分になってきた。本研究の目的は，衝撃的騒音のパッシブな低隇对策法 の一つであるトンネル出ロにボックスを設ける方法の低隇効果を確認することである。本報では，まず円形断面の管内 を圧力波が伝ぱし，開口端から放出され衝撃的騒音が形成されるまでを数值解析した。この計算結果を用い，低隇ボッ クス内の流れ場を数值的に可視化し，衝撃的騒音の低隇メカニズムを明らかにした，さらに：ボックスの形状をさまざ まに変化させた解析により，トンネル出口ボックスの最適な形状が明らかになった。

\section{2. 数拨解析方法}

図 1 に示すように，無限大に大きなバッフル板が管軸に垂直に取 り付けられている直径Dの開口円管の出口端に, 衝撃的騒音低隇の ためのパッシブコントロール用の出ロボックスが設置されていると 考え，压力波が管内を左から右へ伝ぱし，開口端で大気に放出され るとする．流れは管軸に对し对称であると仮定し，円管の管軸方向 すなわち管内を肚力波が伝ぱする方向に出口ボックスの開口端を原 点として $\mathrm{x}$ 軸, 半径方向を $\mathrm{y}$ 軸, 任意の点までの距離を $\mathrm{r}$ 軸, 管軸 からの角度を $\theta$ 軸とする平面で考える.

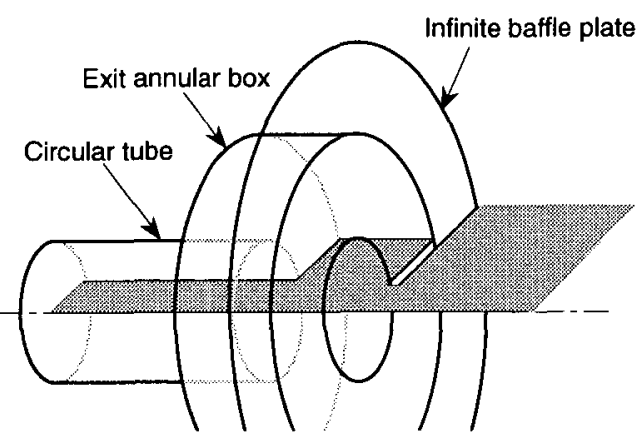

流れの基䃈方程式は質量保存, $\mathrm{x}$ 及び $\mathrm{y}$ 方向の運動量保存, 工ネ ルギー保存の式であり，保存系で次式のようにかける。

$$
\begin{aligned}
& \frac{\partial \boldsymbol{U}}{\partial \mathrm{t}}+\frac{\partial \boldsymbol{F}}{\partial \mathrm{x}}+\frac{\partial \boldsymbol{G}}{\partial \mathrm{y}}+\boldsymbol{W}=0 \\
& \boldsymbol{U}=\left[\begin{array}{c}
\rho \\
\rho u \\
\rho v \\
e
\end{array}\right], \boldsymbol{F}=\left[\begin{array}{c}
\rho u \\
\rho u^{2}+p \\
\rho u v \\
(e+p) u
\end{array}\right], G=\left[\begin{array}{c}
\rho u \\
\rho u v \\
\rho v^{2}+p \\
(e+p) v
\end{array}\right], \boldsymbol{W}=\frac{1}{y}\left[\begin{array}{c}
\rho v \\
\rho u v \\
\rho v^{2} \\
(e+p) v
\end{array}\right]
\end{aligned}
$$

ここに $\mathrm{t}$ は時間， $\rho$ は密度， $\mathrm{u}$ と $\mathrm{v}$ は軸および半径方向の速度, $\mathrm{p}$ は圧力である。また， e は単位体積当たりの全エネルギーである。 これらの式をTVD法3)と演算子分割法4)を用いて数值解析する.

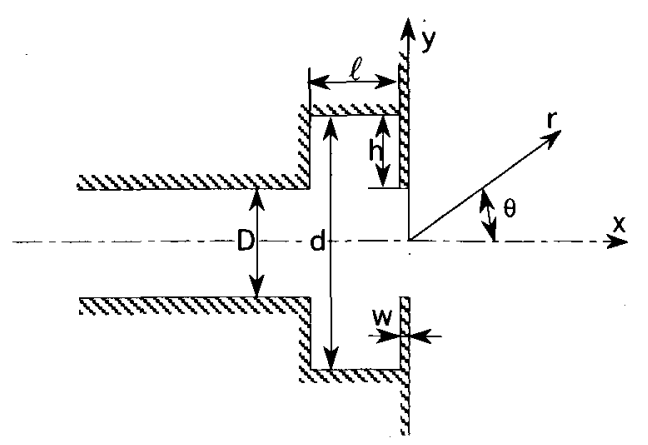

Fig.1 Geometry and computed field

\footnotetext{
* Graduate School of Engineering Sciences, Kyushu University, Kasuga, Fukuoka, 816
} 
計算は図1に示す計算面で行われた．図に示すように，出口ボックスは同心形状しておりその内径を $\mathrm{d}$, 高さを $\mathrm{h}$ $(=(\mathrm{D}-\mathrm{d}) / 2)$, 幅を $\ell$, 出口の壁の厚さをwとする. 計算の初期条件, すわわち $\mathrm{t}=0$ における圧力波の初期波形とし て, 列車が突入することによりトンネル内に形成される圧縮波の半経験式1)を参考にして，次式で示す圧力波を出口 ボックスの入口に仮定する.

$$
\frac{\Delta p_{i}}{p_{1}}=\frac{\Delta p^{*}}{p_{1}}\left[\frac{1}{2}-\frac{1}{\pi} \tan ^{-1}\left\{\frac{\pi}{L}\left(x+\frac{10}{3} D\right)\right\}\right]
$$

上式の $\Delta p_{i}$ と $\Delta p^{*}$ はゲージ圧, $p_{1}$ は圧力波前方の静止気体の圧力である， $\Delta p^{*}$ は圧力波による圧力上昇值，Lは圧力波の 波面の長さを表す， $L \cong 0$ の場合，式(2)は衝撃波の波形を， $L>0$ の場合，圧縮波の波形を表す．計算格子は，管内にお いて半径方向に9, 軸方向に160, 管外においては40×40を基準值とし，必要に応じてその倍数を使用した。

\section{3. 解析結果と考察}

\section{1 出口ボックスがない場合}

まず，出口ボックスがない場合に，管内の衝撃波 㧍よび圧縮波が管の開口端から放射され，管外に形 成される時のパルス波の圧力波形の時間的変化を図 2 と 3 に示す。図では, 内径 $\mathrm{D}=75 \mathrm{~mm}$ の管を用い て得られた実験結果5)も比較のため示してある。図 より分かるように，数值計算と実験結果の圧力波形 はよく一致しており，本数值計算は十分な計算精度 を持っていることがわかる。また，図2の衝撃波の 場合, 中心軸上でパルス波は, 他の方向と比べて鋭 いピークを持っており，寸なわち衝撃波により形成 されるパルス波は強い指向性を持っていることをし めしている．図 3 の圧縮波の場合も波形に指向性が 見られるが衝撃波ほど強くない。したがって，出口 ボックスがある場合の衝撃的騒音, すなわちパルス 波のピーク压力の低減量を測定する位置は, 中心軸 上の鋭いピークを避け，な扔かつその特性をよく示 す必要がある，以下本論文では，その測定点を中心 軸から45度方向，距離 $\mathrm{r}=2 \mathrm{D}$ とした，なお，実際の トンネルでの衝撃的騒音(微気圧波)の測定位置は， 線路脇, トンネル出口中心より $20 \mathrm{~m}(=2.22 \mathrm{D})$ が一般 的に用いられており，本測定位置とほぼ同じであ る。

\section{2 出口ボックスがある場合}

円管開口端からの衝撃的騷音のパッシブコントロ ール用の出口ボックスが設置されている場合に，管 内を伝ぱする衝撃波が管の開口端から放射されてパ ルス波が管外に形成され，それが空間的に広がって いく過程の等圧力分布図を図 4 に示す. 図 4 は原図 のカラーの分布図をグレー印刷したもので,ゲージ 圧力がその強さに応じて色分けしてある，また，管 の内径は実際のトンネルの值の $\mathrm{D}=9 \mathrm{~m}$ と, 出口 ボックスを $\mathrm{h}=2.2 \mathrm{~m}, \ell=13.5 \mathrm{~m}, \mathrm{w}=2.2 \mathrm{~m}$ とた。 図より, 最初衝撃波が出口ボックスで反射 $\mathrm{LR}_{1}$, 管内を上流へ反射膨張波が伝ぱする。一方ボックス 内で回折した衝撃波は開口端に達すると膨張波とし

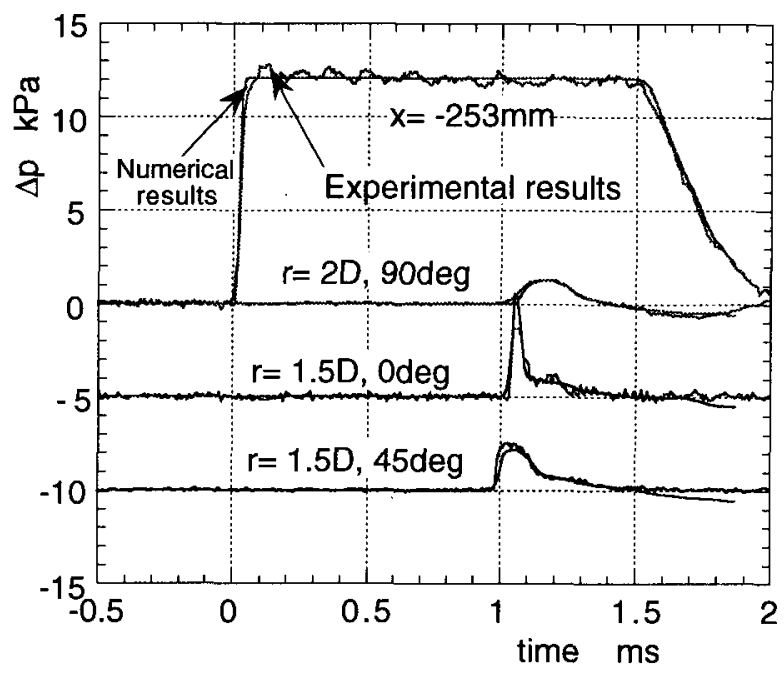

Fig.2 Pressure changes caused by emission of shock wave $\left(\mathrm{D}=75 \mathrm{~mm}, \Delta p^{*}=12.1 \mathrm{kPa}\right)$

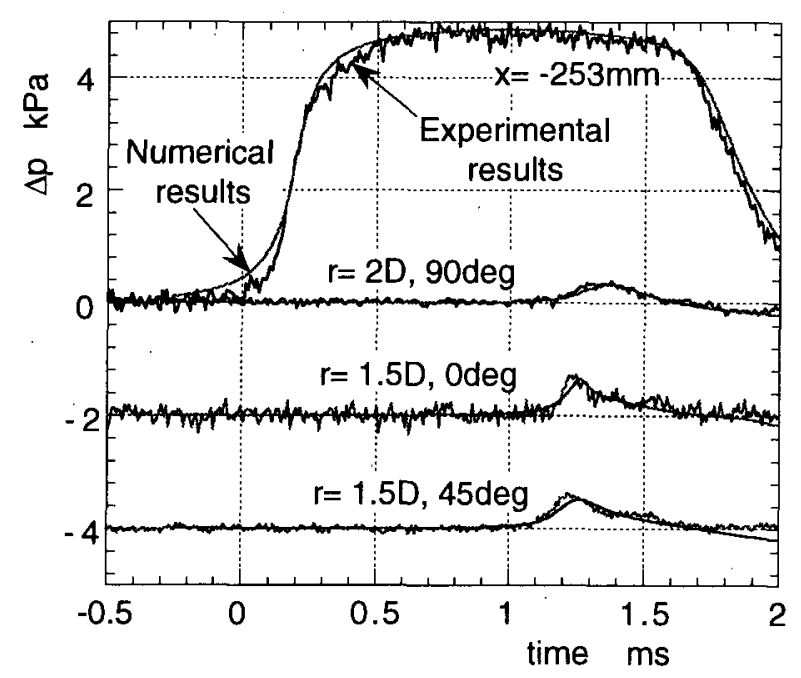

Fig.3 Pressure changes caused by emission of compression wave ( $\mathrm{L} / \mathrm{D}=1.02, \Delta p^{*}=12.1 \cdot \mathrm{kPa}$ ) 


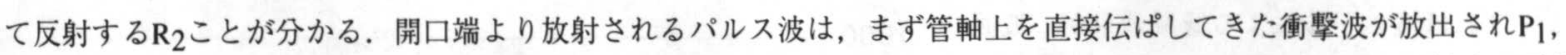
続いてボックスの内壁で反射してきた衝撃波が開口端から放出され $\mathrm{P}_{2}$, さらにボックスの出口内壁からの反射波が再放

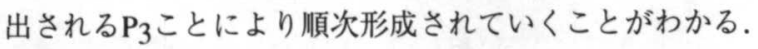

出口ボックスがある場合に得られた衝撃的騒音の波形，すなわちパルス波の圧力波形を図 5 に示す. 測定位置は前述 の参照点(中心軸から 45 度方向, 距離 $\mathrm{r}=2 \mathrm{D})$ で, 初期波形は衝撃波と圧縮波 $(\mathrm{L} / \mathrm{D}=1.0)$ で $\Delta p^{*}=8 \mathrm{kPa}$, 出口ボックスはD $=9 \mathrm{~m}, \ell / \mathrm{D}=2.0, \mathrm{w} / \mathrm{D}=0.06$, である. 図から分かるように, パルス波は 3 つピーク值を持ち, 2 番目のピークが一番大 きい. そこで, このパルス波の最大圧力值を $\Delta p_{\max }$ とする. また, $\mathrm{h} / \mathrm{D}$ が大きいほどその強さは弱くなり, 最初のピー クに対する時間遅れも大きくなる。すなわち, 二番目以降のピーク波形はボックス内の反射, 回折による波の時間遅れ があることを示している.

\section{2 出口ボックスの最適形状}

パッシブコントロール用出ロボックスの最適形状を求めるために, $\Delta p^{*}=8 \mathrm{kPa}, \mathrm{h} / \mathrm{D}=0.222$ の一定とし, 出口ボック

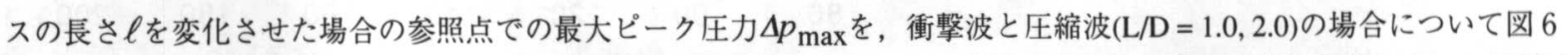
に示す. 図の $\ell / \mathrm{D}=0$ は出口ボックスがない場合を示している. 図より, 衝撃波の場合, $\ell / \mathrm{D}$ の増加と共に $\Delta p_{\max }$ は減少 し, $\ell / \mathrm{D}=0.5$ で最小值になった後, その後ゆるやかに上昇する.これは, ボックスの上壁での波の反射がその低減作用

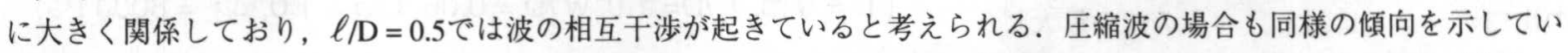
るが, $\Delta p_{\max }$ の低滅率は衝撃波に比べて小さくなる，とくに，L/D=2.0の場合はほとんど低減作用がないことがわか

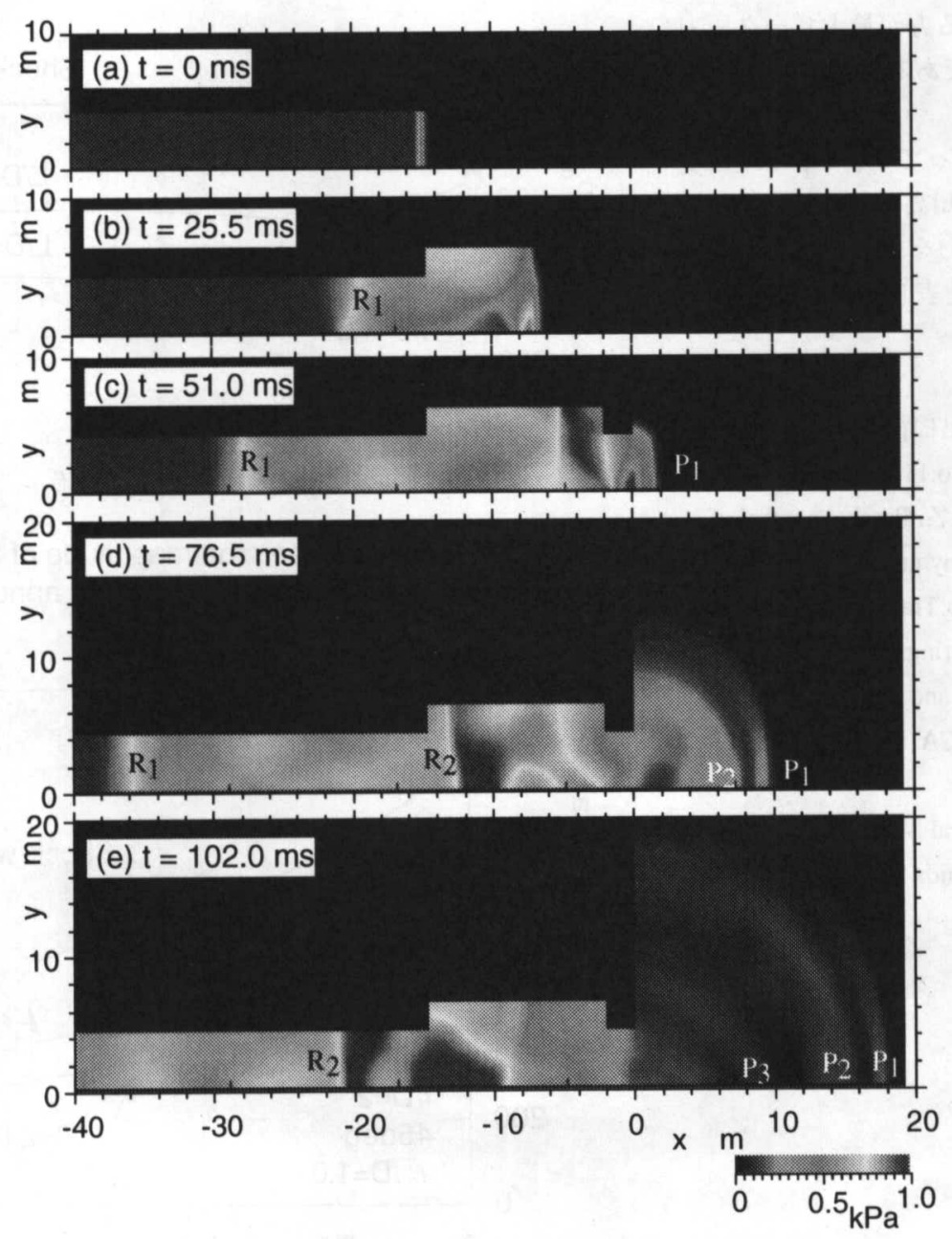

Fig.4 Pressure contours caused by emission of shock wave $\left(\mathrm{D}=9 \mathrm{~m}, \mathrm{~h}=2.2 \mathrm{~m}, \ell=13.5 \mathrm{~m}, \mathrm{w}=2.2 \mathrm{~m}, \Delta p^{*}=1000 \mathrm{~Pa}\right)$ 
る、これは波の干渉による低滅効果が，波面 の幅の中に隠れてしまうためと考えられる。 $\Delta p^{*}=8 \mathrm{kPa}, \quad \ell / \mathrm{D}=1.0$ の一定とし, 出口 ボックスの高さhを変化させた場合の参照点ロ の最大ピーク压力 $\Delta p_{\max }$ ，衝撃波と压縮波 $(\mathrm{L} / \mathrm{D}=1.0,2.0)$ の場合について図 7 に示す. 図 のh/D =0は出口ボックスがない場合を示して いる。図より分かるように，h/Dが大きくな るほど, すなわち出口ボックスの内容積は大 きくなるほど，最大ピーク圧力 $\Delta p_{\max }$ の減少 割合は大きくなる。とくに衝撃波の場合は $\Delta p_{\max }$ の低減率が大きい。

\section{4. 結論}

衝撃的騒音のパッシブな低減対策法として の出口ボックスに対し，パルス波の最大ピー ク压力は, 出口ボックスの内容積が大きいほ ど大きく減少し, 出口ボックスの長さより, その高さを大きくする方が最大ピーク圧力の 低滅に対し，効果的であることがわかった。

謝辞：本研究に当たっては, Dundee大学の A.E.Vardy教授，北九州高専の樫村秀男教授を 始め多くの方々の協力をいただきました。こ こに改めて感謝の意を表します。

\section{参考文献}

1) 小沢, トンネル出口微気圧波の研究，鉄 道技術研究報告書, No.1121, (1974), 1-92.

2) Zeutzius, M. ほか4名, Passive control of impulsive noise caused by unsteady compression wave, Proc 9th Int.Symp.Transport Phenomena in Thermal-Fluids Engineering. (1996), 303-308 3) Yee, H.C., Upwind and symmetric shockcapturing Schemes, NACA TM-89464, (1987), 1127.

4) Sod, G.A., Numerical Study of a Converging Cylindrical Shock, J. Fluids Mechanics, 83-4, (1977), 785-794.

5）(投稿予定)

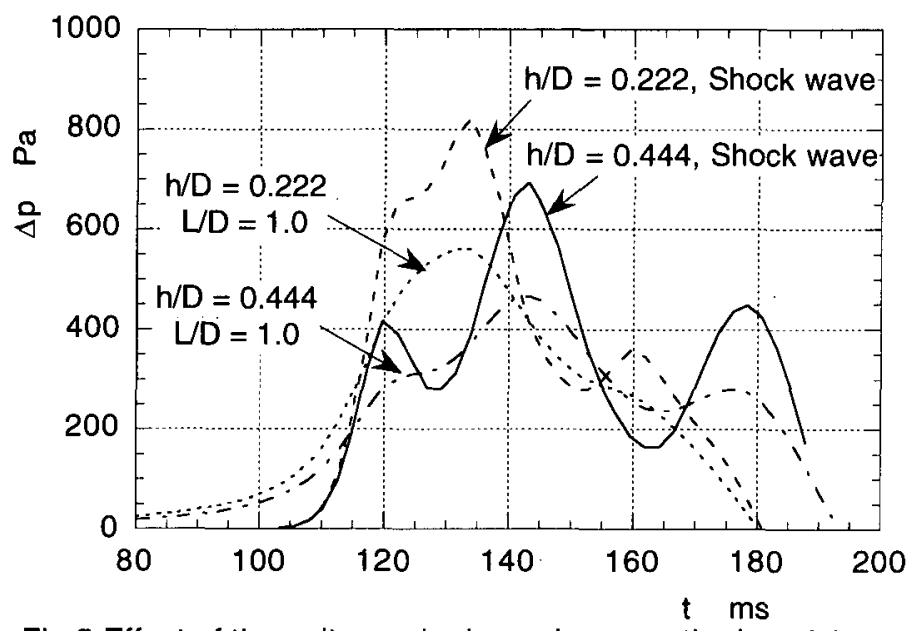

Fig.5 Effect of the exit annular box shape on the impulsive wave $\left(\mathrm{D}=9 \mathrm{~m}, \ell / \mathrm{D}=1.0, \mathrm{w} / \mathrm{D}=0.06, \mathrm{~L} / \mathrm{D}=1.0, \Delta p^{*}=8000 \mathrm{~Pa}\right)$

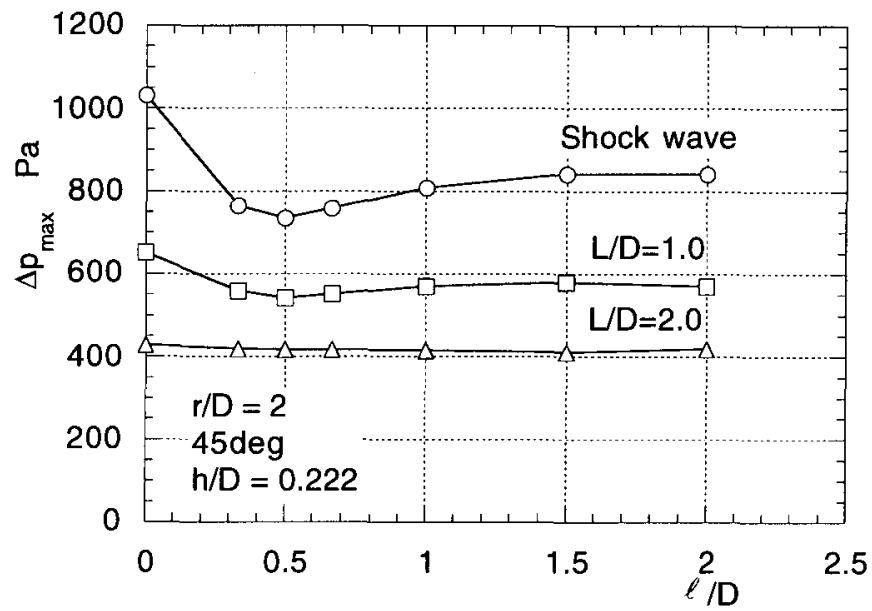

Fig.6 Relation between the magnitude of the impulsive wave and the length of the exit annular box

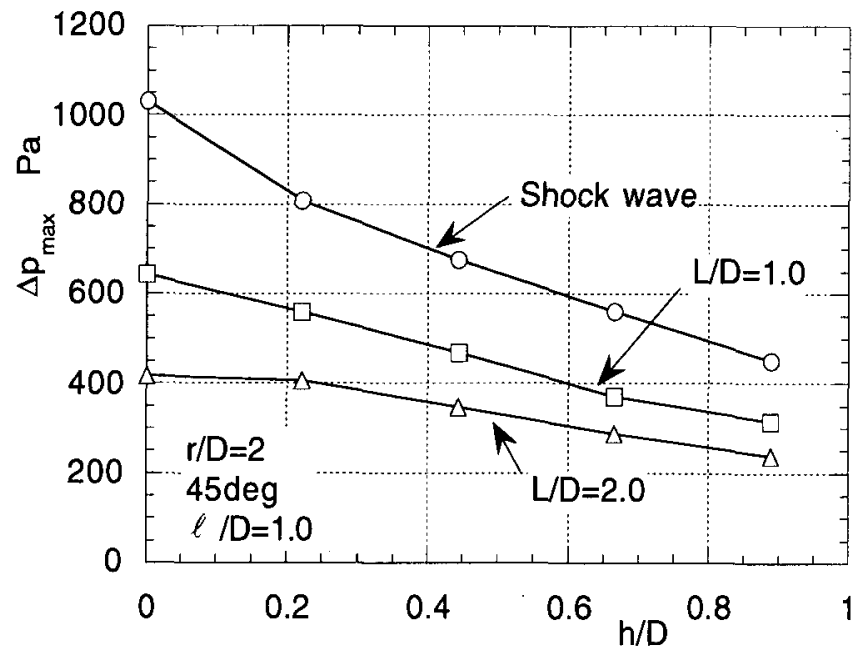

Fig.7 Relation between the magnitude of the impulsive wave and the height of the exit annular box 